\title{
Integrated Waste Management
}

\section{Solid Waste Management Fact Sheet No. 19}

Increasing concern about the environmental impacts of landfilling and new landfill regulations have caused many communities to investigate alternatives to landfills. Most counties and communities have decided to no longer operate their own landfill. However, landfilling still remains the major form of waste disposal. By most estimates as much as $80 \%$ or more of all municipal solid waste in the nation ends up in the landfill. In Kansas that figure may be as high as 95 percent. The rest is recycled or composted. Almost none of the state's waste is incinerated.

But things are changing. Increasingly, communities are beginning to utilize what has been commonly called integrated waste management. Integrated waste management is an approach to managing the waste stream that attempts to segregate the various components of the waste stream and to manage each of those portions of the waste stream in an environmentally sound and economically efficient manner. Along with this, the integrated waste management approach sets priorities as to best choices for managing waste. While not all are equally appropriate everywhere, the management choices in the order they should be considered are:
1. Waste reduction
2. Recycling
3. Composting
4. Incineration
5. Landfilling

By using this hierarchy, only that left over after all of the other management tools have been used ends up in the landfill. For example, a major effort at waste reduction will reduce the overall waste stream without producing a waste that must be managed. The best way to manage waste is to not produce it to start with.

While waste reduction can begin at any level, it seems to have caught hold best in manufacturing. Manufacture of more durable goods, improved repair and repairability of existing products, and less wasteful packaging can all help reduce the waste stream. While waste reduction is an approach that requires corporate policies or regulations to be effective, consumer demand for more environmentally sensitive products is a major force. And many manufacturers have found out that they can actually save money by reducing waste.

Many communities are now employing recycling to further reduce waste volumes that must be handled. Recycling collects reusable material from the waste stream. The recycled material then becomes a commodity used in manufacturing new products. For some materials, such as newsprint and other paper, glass, aluminum, and some plastics, good markets already exist around the country. For other materials, such as magazines, few markets exist but efforts to improve product marketability are growing. Some community efforts around the country have reduced waste volumes through recycling by $25 \%$ or more. As markets for materials have improved, recycling is expanding rapidly.

Much organic waste that is not recycled contains value that further processing can capture. Composting, a natural biological process of decay of organic material, reduces the waste stream into a product that can be used as a soil amendment. Composting has become a very attractive alternative for managing yard waste around the country. Other communities are also investigating solid waste composting to manage the nonrecyclable fraction of the entire municipal waste stream.

Incineration, or the burning of waste to produce energy, has also been an attractive waste processing approach for some communities around the country. Properly operated incineration projects can provide energy in the form of electricity or processed steam, while reducing the volume of waste that must be landfilled by a significant fraction. But it's not for everyone. It usually is only effective on a large scale (serving at least several hundred thousand people). Controlling air emissions from incinerators and properly managing incinerator fly ash and bottom ash are significant challenges for these systems.

Finally, even if communities practice maximum effort at waste reduction, recycling, composting, and/or incineration, a landfill will be needed. A well designed and well-operated landfill is a key component of an effective integrated waste management system. Integrated waste management involves the proper mix of all of these waste management approaches. Integrated waste management will improve environmental protection, decrease potential liability, control waste management costs over the long run, and is expected to be a source of new jobs and economic development.

\author{
Prepared by \\ William M. Eberle \\ Extension Specialist, Land Resources
}

\section{KSSU KANSAS STATF Cooperative Extension Service Kansas State University Manhattan, Kansas}

EP-19 